\title{
Methodology and Tool Support for Adaptive Idea Exploitation in Open Innovation
}

\author{
Sebastian Huber
}

Received: 29 April 2015/Accepted: 2 May 2016/Published online: 22 November 2016

(C) Springer Fachmedien Wiesbaden 2016

\begin{abstract}
The lack of efficiency and transparency regarding cross-company collaboration in the field of open innovation often leads to cost intensive and unsuccessful products and services. This is because traditional approaches fail to cope with emerging requirements in innovation projects, e.g., the vertical and horizontal integration of strategic partners within and across the company's value network. However, to maintain their competitive advantage, companies seek a constant and sustainable development of their product and service portfolio. In this context, knowledge work plays an important role in the collaborative development of innovative product and service ideas. For that reason, knowledge workers need systematic support regarding both methodological and operational challenges. The concept of Adaptive Case Management emerged from the necessity to support knowledge workers in unpredictable and highly creative working environments, especially in the field of Business Process Management. Therefore, the contribution shows, both from a conceptual and technological point of view, how to combine those approaches to support knowledge workers in dynamic innovation projects. To test the validity of the concept, a software prototype serves as the foundation for interviews with experts of the innovation department of a large international industrial company.
\end{abstract}

Dr. S. Huber $(\square)$

Chair of Information Systems, University of ErlangenNuremberg, Lange Gasse 20, 90403 Nuremberg, Germany

e-mail: sebastian.huber@fau.de
Keywords Adaptive case management · Innovation management $\cdot$ Knowledge work $\cdot$ Open innovation

\section{Motivation}

Nowadays, companies face increasing challenges of international competition, globalization of markets, and accelerated technological change (Camphausen 2007). Therefore, it is becoming more difficult to develop and maintain a competitive advantage. One solution to cope with these challenges is to quickly adapt and renew the product and service portfolio (Hauschildt and Salomo 2011). This requires collaboration between customers, suppliers, and partners to introduce successful solutions in the market (Ylimäki 2014). In this context, knowledge workers as the ones with the most entrepreneurial expertise play an important role in the field of product and service development (Muscalu and Stanit 2013).

Over time, the complexity of products and services has increased significantly. In many cases, it is crucial to capture, connect, and exploit the ideas generated by interdisciplinary knowledge worker teams (Howaldt et al. 2011). In particular, the reconciliation of early stages of open innovation (OI) activities incorporates creative activities (e.g., the idea exploitation). These are highly knowledge-intensive and unpredictable. Additionally, in these stages, it is hard to plan upfront which process of knowledge transfer is necessary for the participating partners (Salter et al. 2014). Due to these reasons, it is very difficult to completely design an innovation project in advance (Herstatt 2007; Man et al. 2010), which is contrary to the traditional approach of innovation management (IM).

The same situation applies to the field of business process management (BPM). Traditional business process 
modeling follows a top-down approach (Hangos and Cameron 2001). The process structure is predefined by entirely determining relevant activities, events, actors, documents, tools, etc. The process model shows a strict flow of events and activities following a well-defined logical and chronological order. After having completed the comprehensive process model there is a "roll-out" to the operational level. However, this approach works only with well-structured and plannable tasks, which have to be fulfilled frequently and repeatedly in the same way. In today's business environments, this does not often occur. Often events are unpredictable, activities and decisions are flexible, results are individualized, e.g., have to be adapted to specific customer requirements. However, the accomplishment of these less structured tasks is also part of the approach. Hence, there is a need for task execution models, i.e., process models, which are able to provide flexible goal-oriented guidelines, efficient and adaptive collaboration support, as well as best practice documentation and reuse (Huber 2014).

In this context, Swenson (2010) proposes adaptive case management (ACM) as a new approach for managing knowledge-intensive and less structured work. It explicitly addresses the characteristics of knowledge work and allows the emergence of the procedure, rather than requiring its upfront definition. In doing so, it makes use of an iterative and incremental process model, as well as extensive ITsupport (Matthias 2010; Kurz and Herrmann 2011).

Based on the knowledge-intensiveness and collaborative nature of OI as well as the solutions proposed by ACM (initially designed for the domain of BPM), the objective of this paper is to examine how to merge both concepts into a valuable new approach. By means of a comprehensive software prototype that operationalizes these underlying concepts, this contribution attempts to evaluate the benefits ACM could have to support knowledge workers in planning, coordinating, and structuring especially OI efforts.

\section{Research Methodology}

As the theory of ACM proposes solution approaches to support knowledge-intensive, highly collaborative business processes, the key idea of this contribution is to apply the basic working principles to the field of OI. The assumption is based on the observation, that the traditional innovation process has many characteristics in common with typical BPM approaches. As ACM solutions focus on BPM this contribution tries to adapt key concepts from ACM to the field of OI and seeks proof that they are also suitable to support dynamic and company-spanning innovation projects.

To integrate the fundamental principles of ACM into the context of OI, this work relies on the dynamic capabilities perspective as an augmentation of the resource based view (RBV) of companies (Blome et al. 2013). Basic RBV research emphasizes the heterogeneity of existing resources and their optimal configuration (Teece 2007). The dynamic capabilities perspective enhances this view by focusing "the firm's ability to integrate, build, and reconfigure internal and external competencies to address rapidly changing environments" (Teece et al. 1997). Thus, dynamic capabilities stress the firm's capabilities to develop its resource base aiming at improving the company's competitive advantage (Blome et al. 2013). In the context of OI, a company's ability to perform on a superior performance level lies in its skills to create new processes and services within cross-company value networks that are successful on the respective markets (Teece 2007). Knowledge-intensive tasks exhibit highly dynamic characteristics and experience-based knowledge as an essential company resource that constantly grows in relation to its application. Thus, this contribution stresses a dynamic capabilities perspective to address knowledge as a dynamic resource of a company (Krzakiewicz 2013; Salge et al. 2012).

To investigate experience-based knowledge from the viewpoint of knowledge as a key corporate resource (Krzakiewicz 2013), as a first step the characteristics of OI are depicted based on a comprehensive literature analysis and compared to the field of ACM. Grounded on this theoretical underpinning, the next part shows how to incorporate the procedure, a role model and typical artifacts of ACM into OI. As the idea exploitation phase itself is highly collaborative and knowledge intensive, the scope of this contribution is limited to that phase. To test the validity of the concept, a software prototype serves as the respective research artifact for interviews with experts of the innovation department of a large international industrial company.

\section{Related Work}

\subsection{Open Innovation}

Originally, the innovation process was executed as a linear process (1st generation). Models from that time were commonly influenced by the technology push theory and a strict linear sequence of process steps from research and implementation to the market introduction (Usher 1954, 1955). In the late 1960s, Myers and Marquis (1969) introduced a market pull view on innovation. The authors stated that innovations satisfy wishes and needs of customers on the market (2nd generation). On this basis, the 3 rd generation of innovation models evolved. Mowery and Rosenberg (1979) suggested that all corporate functions 
involved in the innovation process are of high importance and need to be coupled in a meaningful manner. Rothwell and Zegveld (1985) then initiated the prevailing linear approach and postulated that businesses should connect with external entities (e.g., external research institutions). Furthermore, Kline and Rosenberg (1986) extended the linear process models to include various feedback loops (4th generation). The authors stated that the so-called chain-linked model was present in practice, as companies connect corporate functions and external institutions. Within these collaborations, several feedback loops are observed. However, there is a distinction between external research institutions and general available knowledge. Rothwell (1992) postulated the foundation of the 5th generation of innovation process models, based on the chainlinked model of the previous generation. As a result, the interaction and cooperation between different companies in the innovation process was introduced. With this step, the importance of information technology (IT) became evident for the first time, especially with regard to the growing amount of information which had to be processed. With the introduction of the 6th generation, Chesbrough (2003) established himself as one of the first authors to promote the idea of OI (also referred to as collaborative innovation). This reveals that if companies use both internal and external ideas, they can achieve the most effective forms. It also stresses the important aspect of collaboration in innovation process models. Now companies seem to interact with external research institutions as well as external companies and customers. Kotsemir and Meissner (2013) finally suggested that, since the beginning of the 2010s, a new evolutionary stage (7th generation) is about to emerge. As a result, the open innovator model can focus on the individual person and framework conditions under which it is possible to become innovative oneself.

In the evolution of innovation process models, the involvement of external entities has gradually gained importance. Furthermore, the linearity of the process models is enhanced with several feedback loops (Tidd 2006). IT tools become an integral part as the amount of information keeps growing, both from internal and external sources. Over time, it has become a common understanding that innovation follows an interactive and collaborative process. A literature research on the prevailing procedure models mentioned before shows a very heterogeneous landscape. For example, Crawford (1994) and Garriga et al. (2010) determine strategic planning as the preliminary activity in OI. Other authors, such as Thom (1992) and Witt (1996), state that the first activity is the determination of a search field. Most of the authors include commercialization (also referred to market launch) in their model, whereas Hughes and Chafin (1996) do not include this stage, as the last activity in their model is the manufacturing phase. Even though the models vary both in the number of activities and granularity, three major stages emerge from prevailing models of OI (West and Bogers 2014; Folkerts and Hauschildt 2002; Gerpott 2005; Kotsemir and Meissner 2013):

- Idea Generation The first stage (also referred to as fuzzy front-end of innovation) comprises all activities from the early start to the finalized conception of an idea in cross-company teams. This might include the activities of strategic planning, search field determination, preliminary investigations, idea generation, drafting, and conceptualization. Garriga et al. (2010) describe this stage as often chaotic, unpredictable, and unstructured in contrast to the subsequent development of the idea. These attributes are in line with the basic characteristics of knowledge work. In conclusion, the idea exploitation stage is highly knowledge-intensive and determines the success of a project (Man et al. 2010; Beerheide and Katenkamp 2011).

- Idea Development The elaboration (or realization) of an idea is executed in the idea development phase. The corresponding models also refer to this phase as implementation, technical implementation, technical development, production, and manufacturing, depending on the type and subject of the idea.

- Idea Commercialization After the successful elaboration of the idea, the next step is to commercialize and market the innovation to create benefit for the integrated partners both upstream and downstream the value chain (Ylimäki 2014; West and Bogers 2014). This may include the marketing concept, market testing, market launch, and acceptance reviews.

One major challenge of OI is the need for cross-company collaboration and communication (Garriga et al. 2010). Especially challenging for companies are the practical ways to systematically manage and optimize knowledge transfer from external sources into the company (inbound) and to regulate the knowledge transfer from inside the company to external players (outbound) (Salter et al. 2014). The executing knowledge workers lack systematic support for the tasks that arise alongside those challenges (Salter et al. 2014). While returns from OI are maximized when companies foster strong cross-functional and cross-company collaboration (Salge et al. 2012), existing working routines especially in the idea generation phase - are incompatible with the requirements of OI (Salter et al. 2014).

\subsection{Adaptive Case Management}

The first and most prominent publication on ACM is "mastering the unpredictable" edited by Swenson (2010). In this collective volume, the authors describe a variety of individual ideas how to realize and implement the new paradigm. The specifics of the implementation are still 
highly disputed. For example, Pucher (2010) suggests a very comprehensive, domain-independent approach, whereas Matthias (2010) supports a "slim" and specialized system that is tailored to the respective environment. Similarly, Hollingsworth (2010) derives the ACM concept from a healthcare background, while Kraft (2010) relies on customer management, and Man et al. (2010) focus on their individual understanding of IM. Nonetheless, all authors generally agree on main characteristics and define "cases" as the central entity that encapsulates the knowledge-intensive process in ACM.

According to Huber et al. (2013), collaboration is one of the major principles of ACM. Cases, i.e., process instances, are driven by human decision-making using a high degree of freedom and creativity. The interdisciplinary collaboration and co-work are characterized by a growing knowledge base for the execution of a case. At the same time, corrective actions and adjustments of the process by involved parties help responding to external factors or unforeseen disturbances. One major characteristic of a case is the unpredictability of the way to achieve the desired output. In order to follow this concept of guided flexibility, which is also widely recognized in business practice for knowledge-intensive business processes, a paradigm-shift from a top-down to a bottom-up approach can be observed (cf. Fig. 1).
So far, the planning of traditional (open) innovation and project management approaches has been predominantly top-down oriented (Reichwald and Piller 2009). This means that first the organizational and process-oriented structure of cross-corporate innovation activities is defined and deployed. Subsequently, the innovation projects follow a given well-documented plan. Strictly predefined knowledge transfers, both inbound and outbound, are closely monitored during their execution. In contrast, in a bottomup approach cases focus on interdisciplinary cooperation while performing the work across formal organizational boundaries. Cases may use existing templates and best practices, derived from similar successfully accomplished cases. The case execution is simultaneously dynamic and emergent. The classical planning and execution phases merge.

Huber et al. (2014) illustrate this comprehensive view of ACM schematically (cf. Fig. 2): In a case, the involved humans contribute their individual knowledge bases to a predefined common goal. A knowledge base that grows over the execution time characterizes the interdisciplinary collaboration and co-work. At the same time, corrective actions and adjustments of the process are possible for the parties involved in order to respond to external factors or unforeseen disturbances.

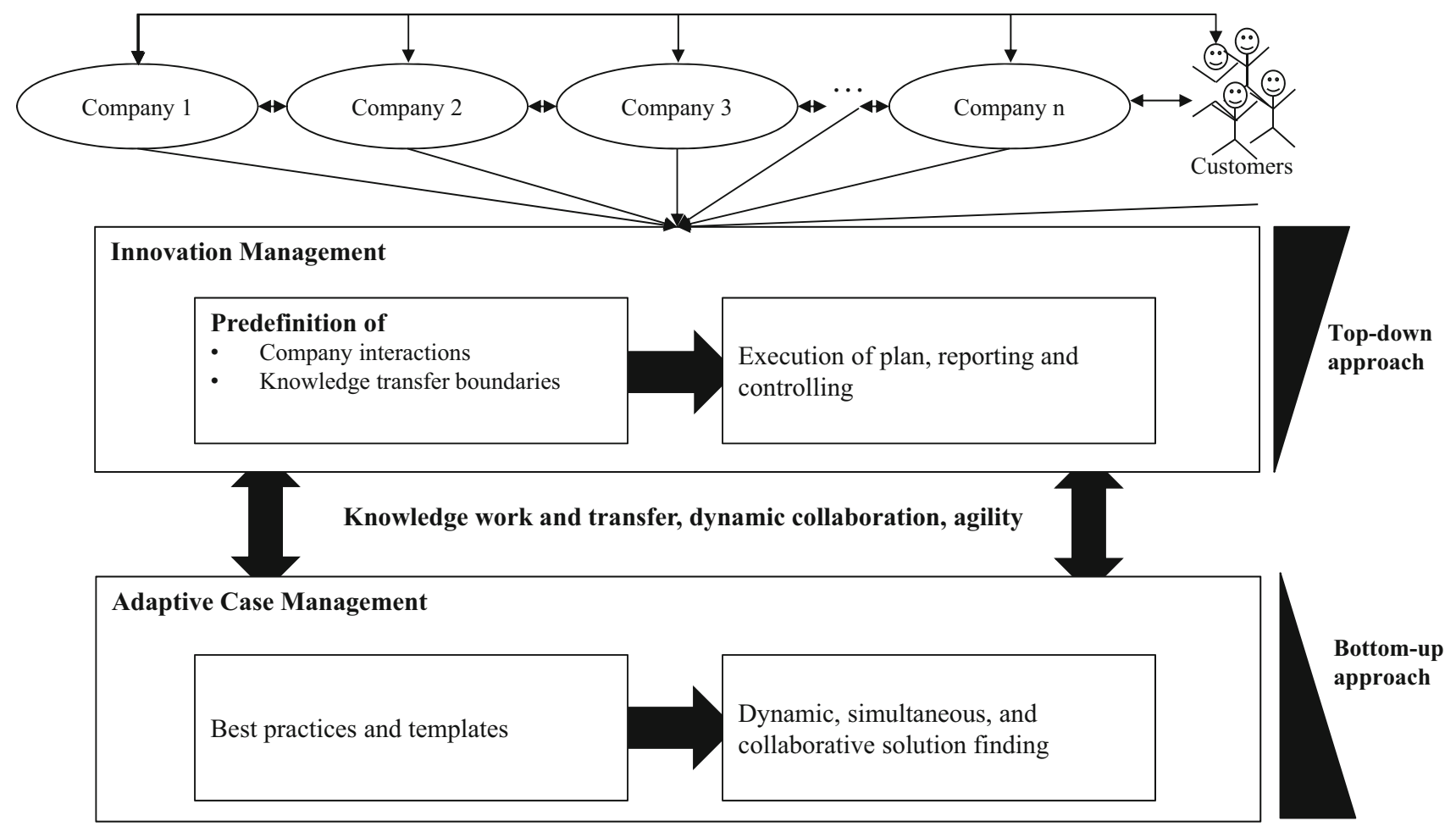

Fig. 1 Paradigm-shift in open innovation 
Fig. 2 Overview of adaptive case management

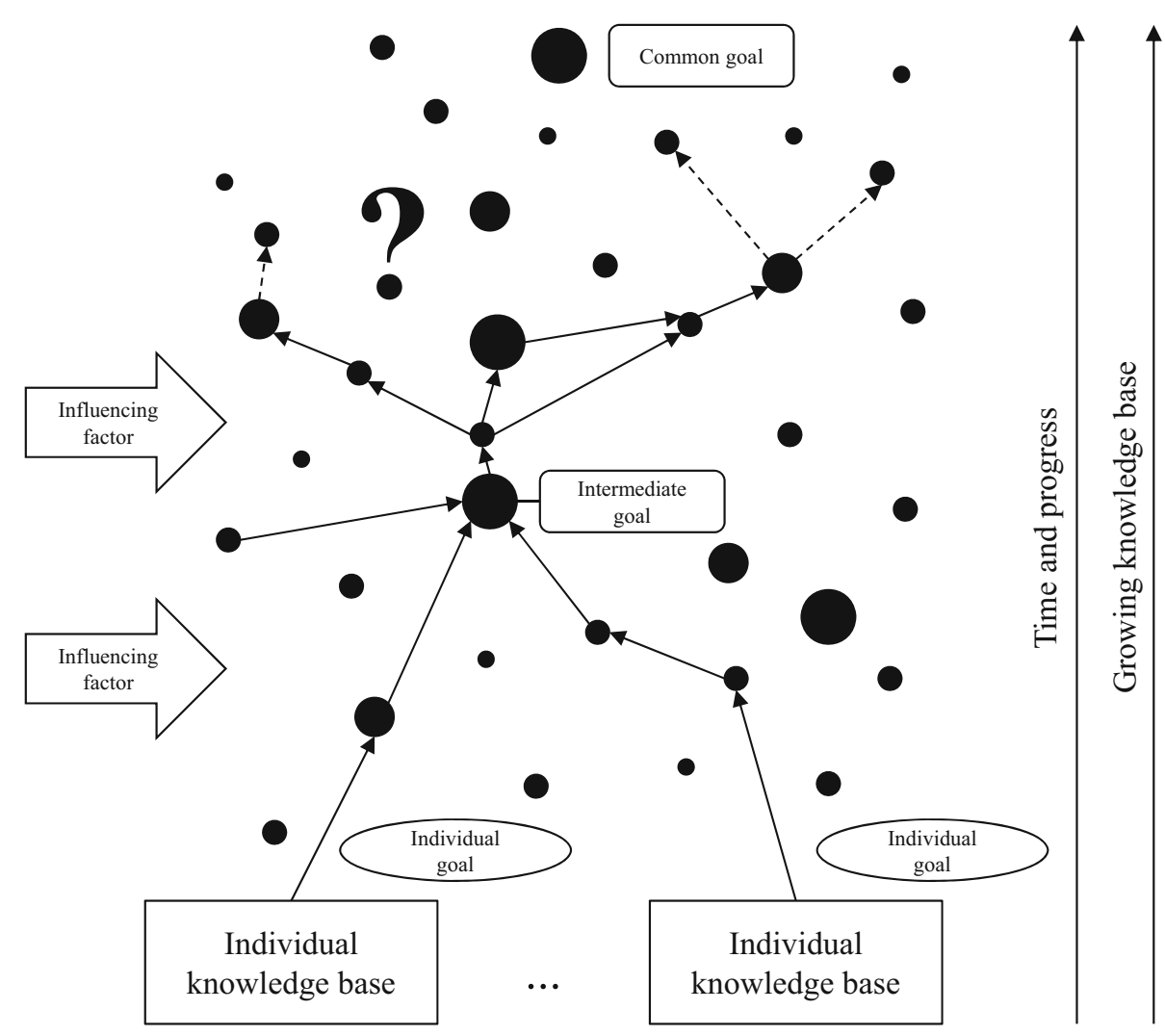

\section{Adaptive Idea Exploitation}

\subsection{Procedure Model}

The exploitation stage is also referred to as the fuzzy frontend of innovation processes (FFE). Its goal is to exploit an idea into a sound concept (West and Bogers 2014; Folkerts and Hauschildt 2002; Gerpott 2005; Kotsemir and Meissner 2013). This stage is often described as chaotic, unpredictable, and unstructured. These attributes are comparable with the basic characteristics of knowledge work and the ACM approach. Thus, the exploitation stage is highly knowledge-intensive (Man et al. 2010; Beerheide and Katenkamp 2011). Furthermore, it encompasses great need for cooperation and collaboration among the participating actors (West and Bogers 2014). Especially in this stage, the particular demands on the constellation and configuration of collaboration across company boundaries are highly dynamic (Ylimäki 2014). In consequence, predefined collaboration approaches fail to achieve their required level of performance (Kolfschoten and de Vreede 2009). This insufficient level of performance is mainly expressed in an unfair distribution of knowledge among the participating project partners. Huber (2014) describes an iterative-incremental model for ACM while Man et al. (2010) propose the iterative-incremental SCRUM model for OI. The derived model comprises those two contributions. Hereby, the entire ACM cycle including initialization, execution, and case-specific adaption, as well as reflection and case-spanning adaption, is progressed as one case. Figure 3 depicts the resulting procedure model for the exploitation phase.

The initialization phase consists of creating a new case (idea) or by instantiating a new case from an existing template (Khoyi and Swenson 2010; Burns 2011). After the case is set up, the actual progression starts with the execution phase. During the case-specific adaption phase, the knowledge workers adapt the case itself. For example, tasks can be added or modified. It is incrementally adapted to its individual circumstances and thus emerges over time (McCauley 2010; Kurz and Herrmann 2011). It follows the four-step Plan-Do-Check-Act (PDCA) cycle of Deming (1988). According to this, the case-specific adaptions are planned first and then executed. Afterwards, there is a comparison between the achieved results and the results expected in the planning. Finally, the differences have to be analyzed and corrected during the act activity and, if necessary, upcoming iterations of the PDCA-cycle are improved. This progression is iterated until all goals of the exploitation stage are reached. Subsequently, the case enters the reflection phase, in which the achievements of goals and their efficiency are evaluated. New insights gained from this evaluation can be generalized and made available for further exploitation cases, for example by 
Fig. 3 Derived procedure model for the exploitation stage

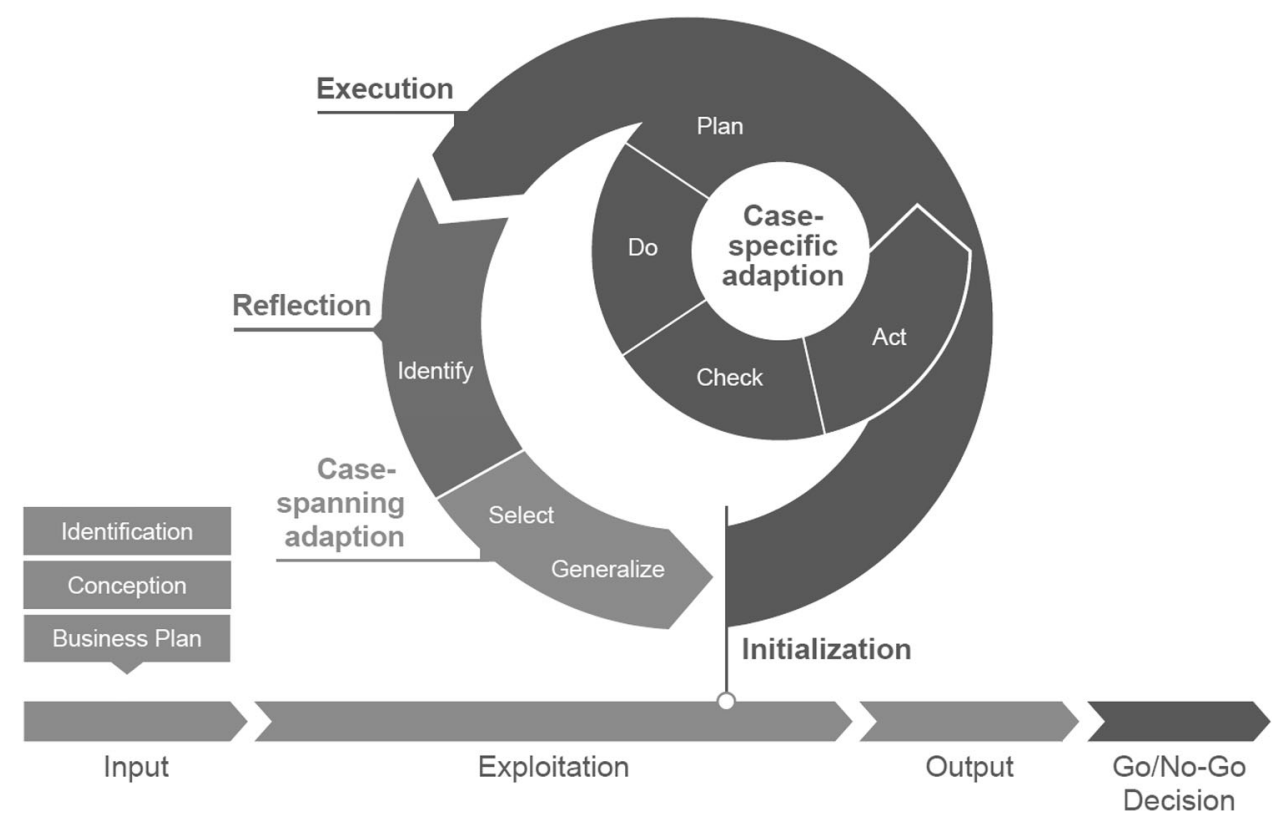

adapting existing templates (Huber 2014). Once this case is finished, a go or no-go decision for the further development of the idea is made to ensure a clearly defined transition. If the decision is positive, a second ACM cycle is progressed for the development stage (Huber et al. 2015).

Inherently, this model also fulfills the requirements of archetypical characteristics of ACM, especially regarding the low degree of structure and adaptivity. The presented stage provides a comprehensive framework for the core activities of OI during idea exploitation without specifying its exact progression. The actual pathway thus emerges while progressing. Based on this overall approach, the following chapter introduces a role model necessary for an efficient exploitation phase.

\subsection{Role Model}

As described in the last chapter, the empowerment of people within the OI process is essential, because their knowledge provides the fundamental basis for idea generation and development. A role model contributes to a secure and efficient cooperation, especially in an IT-based solution. Therefore, this section combines established roles in IM (Chakrabarti and Hauschildt 1989; Witte 1973) and ACM (Kurz and Herrmann 2011):

- The expert promoter (IM) maps onto five of the ACM roles (employee, contributor, innovator, domain expert, and modeling experts). He/she is an employee and works on possible solutions including alternatives to a specific task such as an innovation undertaking. At the same time, the role contributes knowledge, meaning own ideas and information, to the case but is also innovative in the adaption of his/her knowledge base. Moreover, the role acts as domain and modeling expert because he/she has competencies regarding the syntax and semantic correctness of the necessary case proceeding.

- To exert organizational influence is the main task of the sponsor promoter (IM), which comprises the controller, manager, and champion roles in ACM. First, he/she provides the essential monitoring for the innovation project, which stands for the controlling of cases. Second, as a manager, the role is in charge of the availability of resources as well as their strategic alignment. Third, lobbying the decision makers and promoting valuable ideas characterizes his/her task.

- The role of a process promoter (IM) determines the procedure and combines the method expert and the responsible person (ACM). Both have in common that they have an overview over the relevant case context and support individual (case-specific) as well as general (case-spanning) adjustments.

- The relationship promoter (IM) links to the mediator (ACM). He/she has specific competencies in the management of social interactions as well as interpersonal relations.

As the expert promoter (IM) contains many ACM roles, two roles reflect the contributing and problem-solving role in a certain domain. Moreover, a few more roles become necessary in order to handle cases efficiently in an IT-based solution. At the same time, a re-naming of the roles aims at making the new developed roles more explicit. The following seven roles are chosen: 
1. Owner $-\mathrm{He} / \mathrm{she}$ has the initial idea and creates the case (as well as sub-cases). At the same time, this knowledge worker has a special interest in the case and promotes the activities within the collaboration community in the exploration phase. Since this role is actually more technical-oriented (e.g., rights to design cases, etc.) it has no counterpart in the traditional ACM and IM role concepts.

2. Contributor (employee, contributor, innovator in ACM) - This role groups typical knowledge workers who are able to provide the necessary information to perform tasks. They collaborate and make suggestions to solve the assigned case tasks.

3. Expert (domain expert, modeling expert in ACM) Again, this role reflects a typical knowledge worker but employees in this role have expert knowledge either in specific domains or can provide alternative solutions from other fields.

4. Moderator (mediator in ACM) - This role promotes or organizes social relations. Typical tasks are the management of interaction on a platform or the resolving of conflicts if they appear. It is necessary that all other roles accept this mediating role.

5. Innovation Manager (controller, manager, champion in ACM) - He/she manages the overall innovation by providing and coordinating the necessary resources and maintaining the strategic fit. This role has considerable influence on the acceptance within the entirety of the involved organizations.

6. Process Coordinator (method expert, responsible in ACM) - This role maintains the overview of the entire context. Key activities are to determine processes and sequences and to coordinate people and processes. This requires an in-depth knowledge of ACM in general, of its case structures, and of the concept of goal-orientation.

7. Administrator - This additional technical role is necessary to secure the operability of the IT system. $\mathrm{He} / \mathrm{she}$ has the right to access and manipulate all entities (e.g., users).

Figure 4 gives a summary of the roles and shows their involvement in the exploitation phase.

\subsection{Artifacts}

In addition to the role model, specified inputs, tasks, and outputs are required to cover the entire FFE. For that reason, the content perspective of the exploitation stage is derived from the CCC-Model of Schwarz (2014). The author divides this model into three phases (identification, conception, and business plan). Each phase has various tasks and outputs attached to it. As the iterative-incremental model does not involve a predefined execution sequence, the knowledge workers are granted a high level of autonomy, because it is assumed that they have the ability to determine the most efficient way on their own (McCauley 2010; Davenport 2005). Thus, the tasks can be progressed in arbitrary order until reaching the desired outputs. Figure 5 depicts the three phases including their tasks and outputs.

Concluding, the framework proposed (especially in the exploitation stage) consists of an iterative procedure model.
Fig. 4 Consolidated role model of the exploitation stage

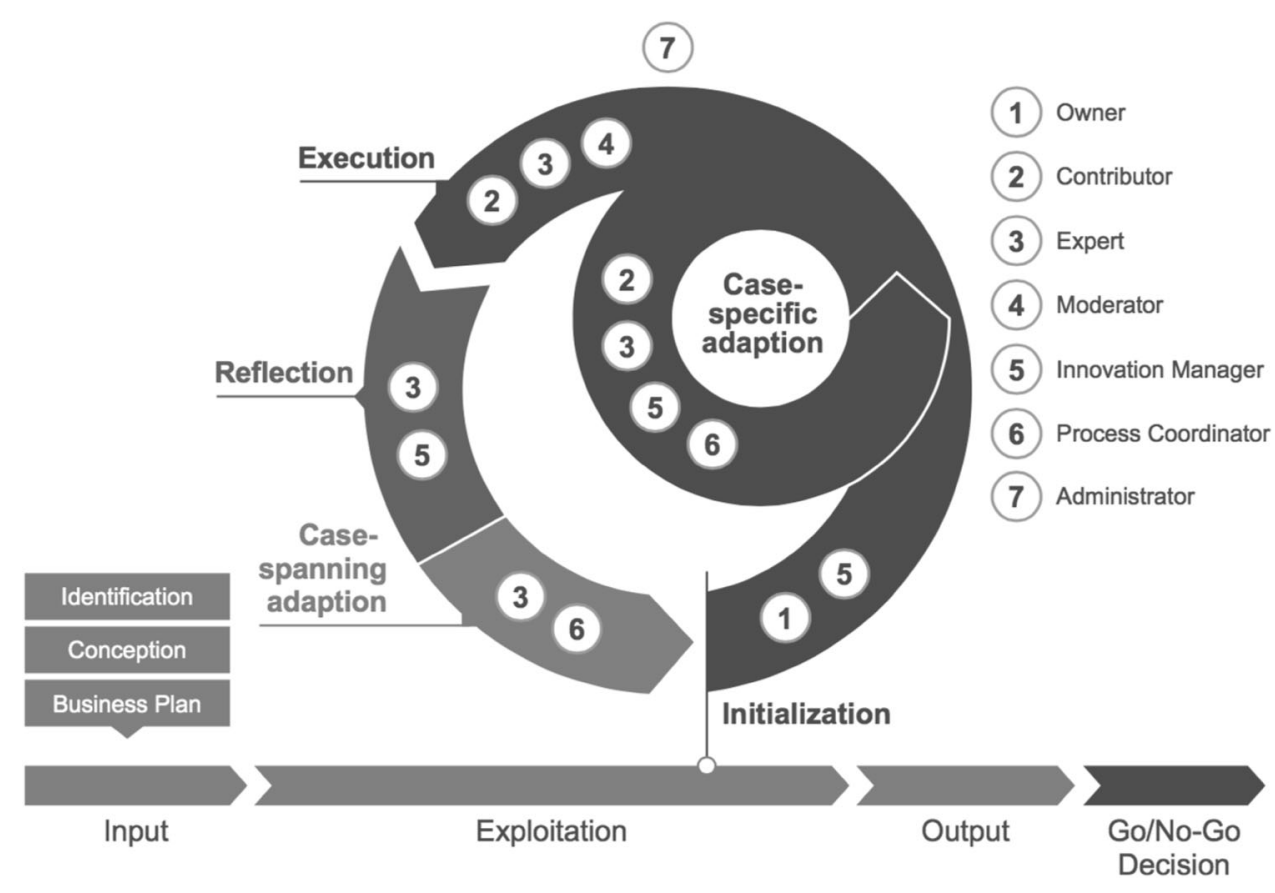




\begin{tabular}{|c|c|c|}
\hline Identification & Conception & Business Plan \\
\hline $\begin{array}{l}\text { - Define the idea } \\
\text { - Roughly describe the idea } \\
\text { and the respective problem } \\
\text { - Identify and describe the } \\
\text { novelty } \\
\text { - Define the respective internal } \\
\text { or external customers } \\
\text { - Determine the corresponding } \\
\text { advantages } \\
\text { - Examine the fit between the } \\
\text { idea and the strategy, mission } \\
\text { statement, and vision of the } \\
\text { company } \\
\text { - Roughly investigate the } \\
\text { compliance of the idea with } \\
\text { legal, political, and social } \\
\text { principles }\end{array}$ & $\begin{array}{l}\text { - Describe the idea in detail } \\
\text { - Investigate the competitive } \\
\text { structure regarding } \\
\text { substitution, competitors, } \\
\text { customers, suppliers, and } \\
\text { rivalry in the market } \\
\text { - Examine the size and growth } \\
\text { of the market regarding size } \\
\text { and process of growth } \\
\text { - Specify the technical } \\
\text { feasibility and risks } \\
\text { - Specify the organizational } \\
\text { feasibility and risks } \\
\text { - Estimate potential synergy } \\
\text { effects } \\
\text { - Ensure legal, political, and } \\
\text { social compliance }\end{array}$ & $\begin{array}{l}\text { - Extend the idea description } \\
\text { to a comprehensive concept } \\
\text { - Assess the competitor } \\
\text { structure and market } \\
\text { structure in detail } \\
\text { - Analyze and estimate the } \\
\text { expenses for the technical } \\
\text { realization } \\
\text { - Assess the value of } \\
\text { synergy effects } \\
\text { - Estimate the risk in } \\
\text { monetary values } \\
\text { - Specify figures for costs, } \\
\text { price or savings, capital } \\
\text { commitment, and } \\
\text { development time }\end{array}$ \\
\hline $\begin{array}{l}\text { - Short description of the idea } \\
\text { - Novelty of the idea } \\
\text { - Advantages of the idea } \\
\text { - Internal and external } \\
\text { customer definition } \\
\text { - General strategic fit of the } \\
\text { idea } \\
\text { - Basic compliance regarding } \\
\text { legal, political, and social } \\
\text { principles }\end{array}$ & $\begin{array}{l}\text { - Specific description of the } \\
\text { idea } \\
\text { - Information about the market } \\
\text { and the customer } \\
\text { - Technical and organizational } \\
\text { risks } \\
\text { - Potential synergy effects } \\
\text { - Ensured compliance } \\
\text { regarding legal, political, } \\
\text { and social principles }\end{array}$ & $\begin{array}{l}\text { - Specific concept of the idea } \\
\text { - Detailed knowledge } \\
\text { regarding the competitive } \\
\text { and market structure } \\
\text { - Expenses and costs } \\
\text { - Monetary value for synergy } \\
\text { effects and risk } \\
\text { - Economic figures for final } \\
\text { decision }\end{array}$ \\
\hline
\end{tabular}

Fig. 5 Tasks and outputs of the exploitation stage

Each phase comprises respective roles and artifacts (e.g., inputs, tasks, and outputs). This concept serves as a foundation for best practices (templates).

\section{Tool Support}

In order to evaluate the framework, an initial software prototype serves as the respective research artifact. The most important feature in the idea exploitation phase is the concept of case extensions. They provide a modular suite of collaboration functionalities to adapt the workspace during case execution. In this way, the collaboration platform initially shows fundamental components that are required for small innovation projects. As a case grows over time, new functions could become necessary and be attached easily. Thus, the extensions enable the dynamic adaption of knowledge transfer between the participating partners. Another important aspect is the collaboration concerning different business objects, like tasks, documents, and decisions across company borders. Typical software solutions treat these objects in separate navigational views and functions, respectively, and are strictly limited to a company internal scope. They do not provide the option to create relationships between those business objects and between different organizations.

An innovative approach in that regard, which directly supports collaboration, is the idea workspace. With an intuitive "drag and drop" behavior it is possible to create different lists and freely arrange all objects used in the case. By doing so, hierarchical relationships between tasks (e.g., milestones, subtasks) or the assignment of documents to discussions, etc., can be realized (cf. Fig. 6).

A second example for the IT support during the idea exploitation phase is the evaluation of the overall idea in a cross-company team by applying a multi-criteria evaluation schema as shown in Fig. 7. For the example presented below, the involved team members can assess five evaluation criteria (priority, risk, practicability, degree of innovation, and relevance). A spider chart visualizes the 


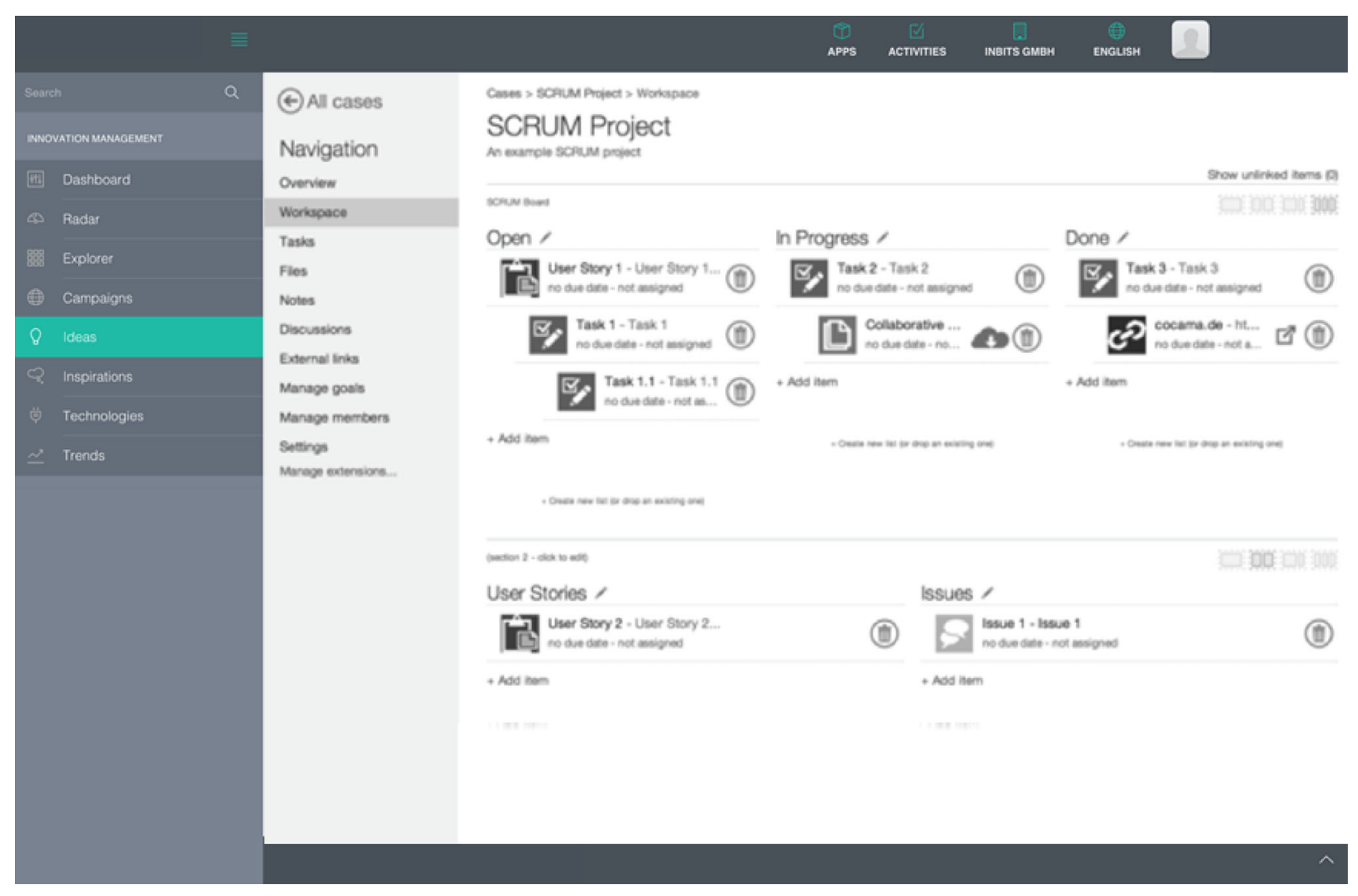

Fig. 6 Idea exploitation workspace

estimated values. Building the arithmetic mean of all available assessments, the system calculates and displays the overall idea evaluation.

In addition to the examples given above, the software tool allows to comprehensively report and control innovation projects within and across companies. Figure 8 shows a dashboard comprising a brief overview of the existing cases in the system and contains information about current challenges, ideas, and projects. The pie chart visualizes the currently pursued ideas grouped by challenge.

\section{Evaluation}

\subsection{Procedure}

The results from the derived insights indicate the need for both a conceptual and a technological solution for OI, at least in theory. To prove the findings in practice, the Design Science Research Methodology suggests evaluating the findings in order to observe how effective and efficient they are (Hevner and Chatterjee 2010). For this reason, the innovation department of a large international industrial company conducted the evaluation as an evaluation partner. Before this innovation program was launched in 2014, ideas were already managed, but in a rather unstructured way. The goal of this specific program was to increase the quality of the submitted ideas and to generate more value out of the ideas of employees. In the beginning of the evaluation, a brief analysis of the as-is situation was conducted. Both the prevailing processes and the existing software tool were deemed as outdated during an internal presentation by the innovation department. After a few bilateral discussions with the program manager, an agreement was reached that the proposed concept and software prototype should be evaluated in terms of the program.

The semi-standardized verbal expert interviews were based on a predefined guideline. It was designed based on the derived components as described above. At first, the aim was to examine whether the presented model was considered applicable in the practice of open innovation. Subsequently, the interviewed experts discussed the relevance and necessity of the derived tasks, outputs, and templates during the exploitation stage. The reason behind this was to study whether these substantive elements of the iterative-incremental model are actually found in practice. For the role perspective, the derived roles and competencies were evaluated regarding their availability and applicability at the evaluation partner company. The interviewees also explained what roles or competencies 


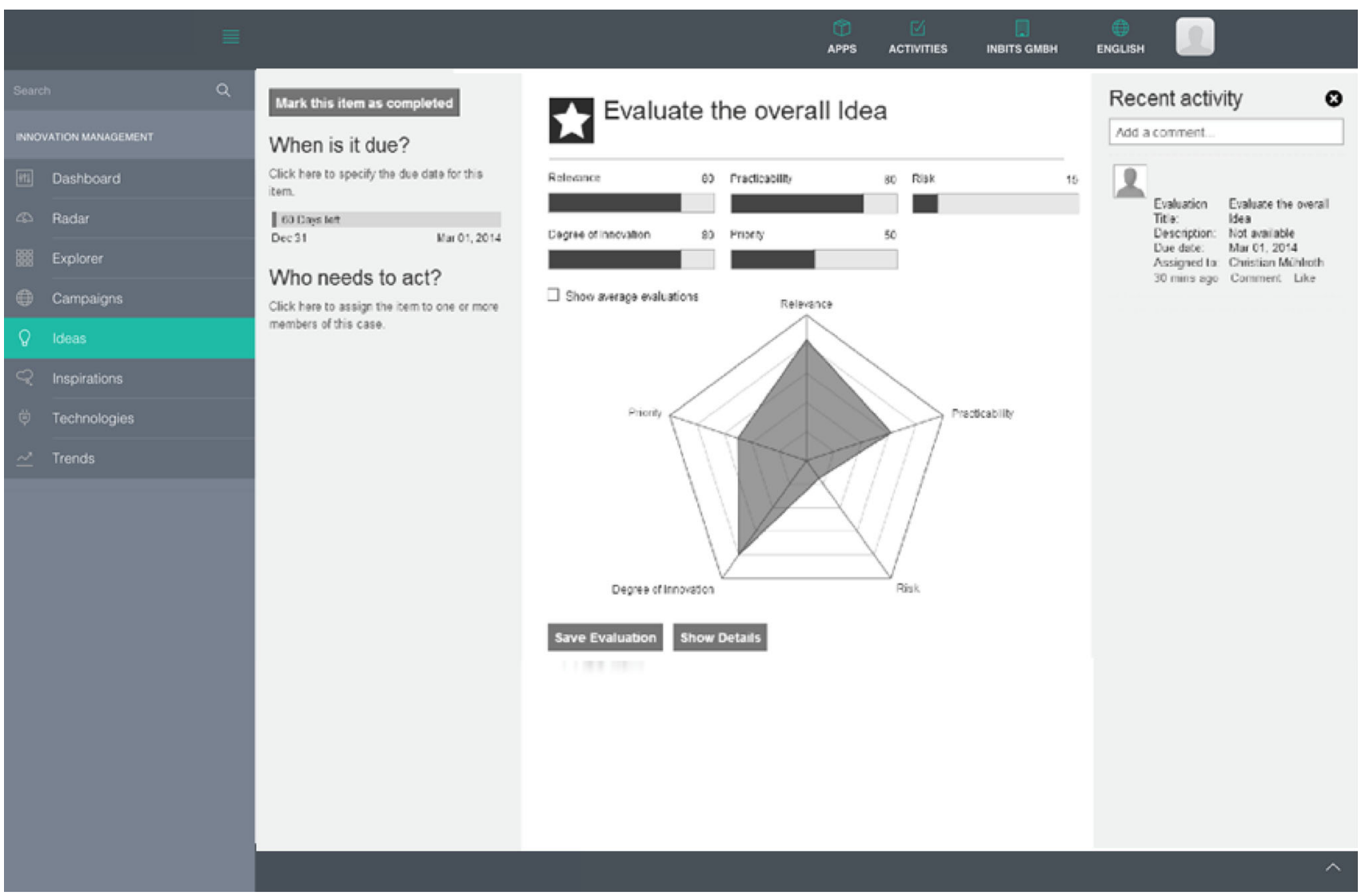

Fig. 7 Idea evaluation

were missing in the role model. If any competencies were assigned to wrong roles, the correct allocation was discussed. The second part of the interview presented the proposed tool support for the experts. Here, the features and requirements of the tool were discussed. The experts were asked to rate the corresponding functionalities.

During all parts of the evaluation, the five experts (cf. Table 1) were asked to rate each element on a three-point scale: required $(+)$, nice-to-have $(0)$, or redundant $(-)$. Thus, the findings were examined in the context of the evaluation partner and possible further action points were derived during the open discussions.

\subsection{Results}

The tasks, outputs, and templates of the exploitation stage describe the procedure and required tasks on the way from a newly submitted idea to a possible go or no-go decision. Based on the existing processes with the evaluation partner and the existing issues, the experts evaluated the process perspective. In general, the consensus was that the tasks and expected outputs of the exploitation stage could contribute to a higher quality of submitted ideas before the implementation decision. One specific issue with the company's existing process is that ideas can be submitted to the system in any form. This lead to the fact that in many cases, ideas needed to be returned to the submitter because the evaluator felt that he did not fully understand the submission. All of the experts regard a rough description of the idea as a mandatory task, including a definition and the addressed problem. Furthermore, the idea needs to be described in detail. Three experts additionally requested to extend the idea description to a comprehensive concept. Similar, all experts required the identification and description of the novelty and possible advantages for the organization. The compliance of the idea with legal, political, and social principles needs to be checked, and a specification of the technical feasibility and risks is mandatory. At least half of the experts considered all these tasks to be essential for an adequate idea presentation. Those tasks and outputs are summarized in a template. Thus, this template contains the minimum required data and information for an idea. The experts controversially evaluated information about the respective internal or external customers. Two interviewees required this information, whereas the other three regarded this information as redundant. The strategic fit and the ensured compliance of the idea was considered three times as nice-to-have and two times as redundant. Furthermore, information about the size and growth of the market was mentioned once as 


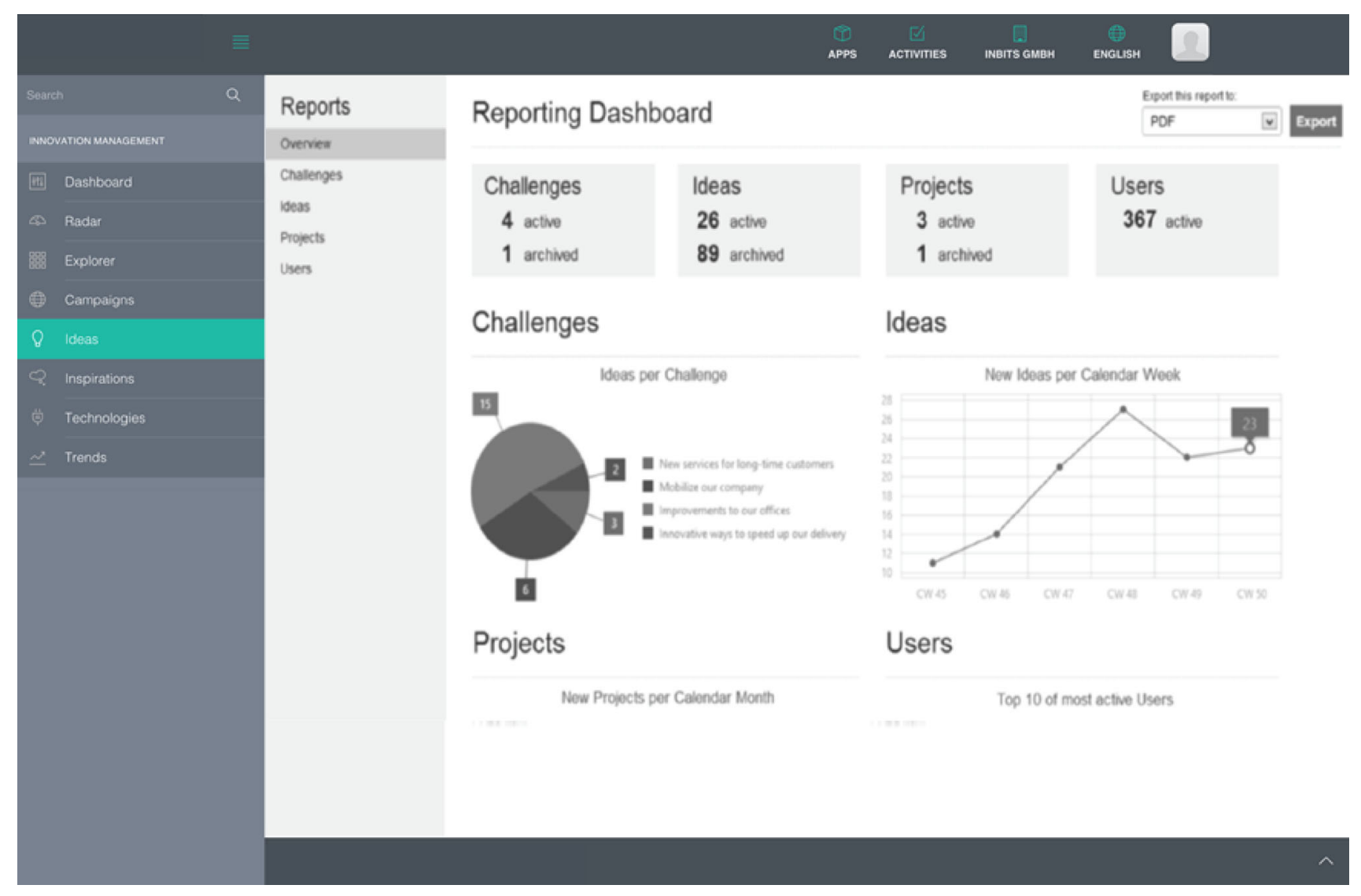

Fig. 8 Reporting dashboard

Table 1 Role and competencies of interviewees

\begin{tabular}{lll}
\hline$\#$ & Role & Competencies \\
\hline 1 & Program manager & $\begin{array}{l}\text { Creative solutions and initiatives for the innovation department; } \\
\text { holistically manage its program } \\
\text { Organizational function; train people in using the existing system; } \\
\text { decision-maker; evaluation role; give rewards; submitter for blue- } \\
\text { collar workers } \\
\text { Receive incoming ideas and reject ideas; decide if the idea is } \\
\text { forwarded to the right evaluator; coordinate the process; communicate } \\
\text { decisions }\end{array}$ \\
3 & Program coordinator & $\begin{array}{l}\text { Supportive administrative role; conducts meetings with finding and } \\
\text { structuring of new ideas } \\
\text { Daily and monthly reporting of development processes; } \\
\text { communication for internal stakeholder (all internal employees who } \\
\text { are in touch with the innovation department) }\end{array}$ \\
5 & System administrator &
\end{tabular}

required, once as nice-to-have, and three times as redundant. Thus, a second template incorporates all information, which is deemed necessary for an idea and its implementation decision. In contrast to that, the experts deemed tasks and outputs of the examination of the competitive structure, detailed parts of the risk plan (organizational feasibility and risks, as well as monetary values), synergy effects, and cost plans as redundant. These elements are seen to belong to the development stage, after a positive implementation decision. Therefore, they are not incorporated in the template for the exploitation stage.

In addition, the experts were asked whether the roles are applicable, whether they are seen as necessary, and whether they are assigned to the appropriate competencies. Table 2 gives an overview of the roles and the answers of the interviewees. It shows that overall there was a high consensus and acceptance. The owner is named as the submitter in the context of the industrial partner. This role 
Table 2 Evaluated roles for the exploitation stage

\begin{tabular}{lllllll}
\hline$\#$ & Exploitation role & Interview 1 & Interview 2 & Interview 3 & Interview 4 & Interview 5 \\
\hline 1 & Owner & + & + & + & + & + \\
2 & Contributor & + & + & + & + & + \\
3 & Expert & + & + & + & + & + \\
4 & Moderator & + & - & + & 0 & 0 \\
5 & Innovation manager & + & + & + & + & + \\
6 & Process coordinator & + & + & + & + & + \\
7 & Administrator & + & + & + & + & + \\
\hline
\end{tabular}

Fig. 9 Assessment of the software prototype

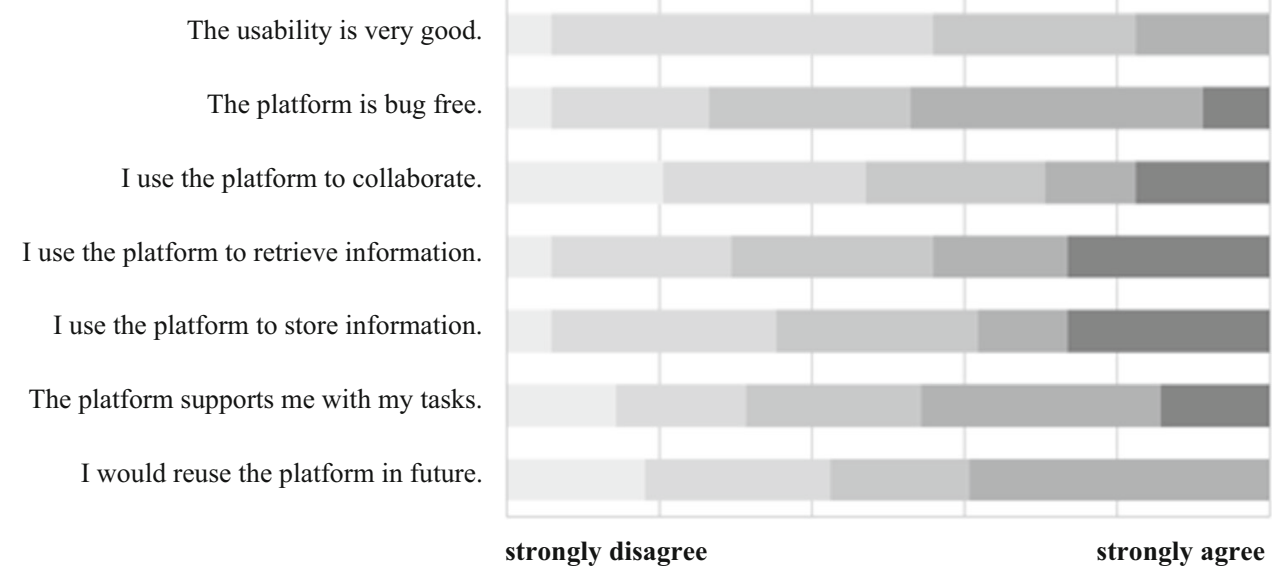

is already available in the existing process and therefore seen as required. In the moment an employee submits a new idea to the system, this role automatically is assigned to him. In contrast, the role of a contributor is currently not available. Nevertheless, this is considered as a mandatory distinction in terms of collaborative OI. The experts of the third and fifth interview especially pointed out the strong need for this role. The expert role is also incorporated in the current process of the evaluation partner. Here it should be noted that the additional role of the evaluator also is incorporated in the role expert, as both roles share the same competencies. The importance of the moderator role was controversial. Interviewees one and three found that this role does not exist in the context of the evaluation partner, but would be helpful in terms of facilitating and communicating the process. Yet, in interview two the role and its competencies, which especially target social and relationship management, was completely rejected. The reason was that this role might produce overheads in terms of communication and coordination, and therefore should rather be incorporated into the role of the process coordinator. Interview four and five both evaluated this role as nice-to-have, but not necessary. The expert in interview four additionally raised the question whether users of the system might feel supervised and therefore might resist using the system. The innovation manager was seen as the central role in which all different parts come together. The current process already includes the role and calls it program manager. Thus, it was well received in the model proposed. In addition to the competencies, interview four mentioned the leadership and culture definition as one main task for this role. The process coordinator maps with the already existing role of the coordinator according to all experts. The need for this role was considered to be very high, especially in terms of the aspect of orchestration. If the separation of blue-collar and white-collar workers is maintained in future, this aspect inherently requires the orchestration of both submission processes. Finally, because an IT tool exists, all also unanimously agreed with the required role of the administrator, especially in terms of the technical administrator to prevent and solve all technical issues of the IT tool. To summarize the above, the derived roles were acknowledged as highly relevant. The only exception is the role of the moderator, originally located in the role as relationship promotor (von Gemünden and Walter 1995; Hauschildt and Salomo 2011). Only the first and the third interviewee saw this role as required, whereas all other roles obtained approval by all experts.

The second part of the workshops consisted of the evaluation of the proposed IT support (cf. Fig. 9). It included the features and requirements, as well as the system design. For this reason, the evaluation of the two parts was conducted simultaneously, without separating them. During the second 
part, each feature and its associated requirements were shown to each expert. Similar to the first part, the interviewees rated each requirement as required $(+)$, nice-to-have $(0)$, or redundant $(-)$. The open discussion climate made it possible to give feedback on each item. After the rating, the experts where asked for additional requirements which were not mentioned in the concept.

The first discussion was based on the non-functional requirements (NFR). As they cannot be resolved into actual functions of the system, no specific use-cases or parts in the tool exist. Therefore, they were solely read out. For usability, all experts agreed that the IT tool should be a browser-based solution. The support of multiple languages was required by four of the five experts, whereas in the last interview this NFR was only rated as nice-to-have. As expected, the easy and intuitive use of the system was rated as required by all interviewees. In the first interview, it was explained that one current issue with the existing IT support is that it is not able to cross national borders. The reason for this is that no global community, no global process, and no flexibility regarding the support of local conditions and environments are supported. Therefore, requirements regarding security and infrastructure were seen to possess an important role. User authentication, including the support of external actors, and the role and permission based user management were particularly rated to be of high importance. With the integration into existing infrastructure and applications, it would become possible to bind both global as well as local IT systems to the tool. For example, interfaces to user directories would enable every employee to simply log into the IT tool. Consequently, all experts rated this requirement as strongly needed. Finally, the automatic generation of system protocols and error logs was stated to be required in combination with the administrator user role.

Following this, the functional features and requirements (FFR) were presented. The creation of new idea cases, as the basic requirement of the entire IT tool, was required by all experts. Three experts required a draft mode, in which the owners of the idea case can edit the case before making it visible to all other users, whereas the other two rated this requirement as nice-to-have. The transformation from an idea to the development stage was rated similar. Idea challenges were only seen as necessary by two interviewees. The case execution includes a similar pattern. All asked experts perceived as a must-have the flexible assignment of users to tasks and the provisioning of functionalities for the idea exploitation stage. Four experts rated the possibility that members of the idea case can add information and information objects (e.g., files and documents) as required. Here, the opinion of the expert from interview three focused on a very fast pass of ideas through the system. Due to this, he rated it only as nice-to-have. The expert ratings of idea evaluation were different than expected. During the first part of the workshops, the issue of evaluators who either do not perform an idea evaluation completely, or perform the idea evaluation based on emotionally driven decisions, was raised. In contrast to this, two experts required a structured multi-criteria evaluation of ideas, whereas three experts rated this functionality as niceto-have. A follow-up on this question revealed that the real issue is believed to be the provisioning of incentives for evaluators, rather than the evaluation itself (interview two, three, and five). It is assumed that the different perspectives on OI cause those contradictory statements. However, all five experts required the possibility to compare ideas to other similar ideas. In interview three, there were comments that a significant part of the time is spent on rejecting ideas which had already been suggested in a slightly different form. In figures, $48 \%$ of the rejected ideas are doublets. Therefore, a functionality that indicates the double entry to the users before the submission would be capable to reduce this overhead. Collaboration and coordination was generally a desired feature of the IT tool. All interviewees agreed upon the fact that collaboration and coordination plays a significant role for the exploitation of an idea. Knowledge needs to be shared and the teamwork on ideas was seen to be beneficial. Yet, the requirements in detail were ranked controversially. Individual activity streams for each case and functions for collaborative discussion and rating were three times assessed as required and two times as nice-tohave. Private messaging, which should enable conversations and prevent the switch to a different system (e.g., e-mail) was only rated twice as required, and three times as nice-to-have. The expert from interview four commented that private messages could be used as chatting functionality outside the context of the actual work, and for this reason he only rated them as nice-to-have. Broadcasting and e-mail functionalities, for example to inform users of new ideas, new initiatives, or general information, were required by all interviewees. A similar rating was received by the personal user dashboard, as an entry point for coordinating and organizing the work of each user. The concept of casespecific adaption, originally derived from ACM, was explicitly well received. As the tool presented this flexible approach, both the adaption of cases during the runtime and the assignment of individual tags to cases were required by all experts. Furthermore, four experts rated the assignment of multiple owners to a case as essential, whereas the expert from the last interview stated this requirement as redundant. The role of this expert is the controller with the evaluation partner. Thus, he is responsible for daily and monthly reporting, and for collecting figures and numbers from the system. He explained that the assignment of more than one user as case owner would cause a lot of controlling overhead, due to existing policies. Consequently, this expert 
completely rejected this requirement. Subsequently, casespanning adaption, also derived from the concept of ACM, was well received. All experts welcomed the administration and adaption of case templates as a method towards time saving activities for the users. The evaluated tasks and outputs of the exploitation stage suggested two different templates (small idea and big idea). In combination with the adopted tasks and outputs, this function was seen to be able to increase the quality of ideas in the system. Consequently, this could have a positive impact on the willingness of the evaluators to evaluate ideas.

\section{Conclusion}

This contribution outlines how the recent trend of ACM could be adapted to improve the way OI can be supported by means of IT. First, the general concepts and principles behind the new paradigm are introduced and put into the broader context of OI. Subsequently, the implied role and challenge of collaboration between knowledge workers is investigated, in order to illustrate the fundamental differences compared to other traditional IT systems for OI. This reveals that predefined collaboration approaches fail to achieve their required level of performance (Kolfschoten and de Vreede 2009). By following the core principles of ACM, this approach shows new ways to deal with the emergent, interdisciplinary, and unpredictable nature of OI which is often highly collaborative (Garriga et al. 2010). As the new approach (especially the iterative-incremental procedure model) breaks with the traditional separation of planning and execution (in fact it merges both phases into one), knowledge workers are provided with a framework that supports the required flexibility and provides a dynamic environment for teamwork across company boundaries. To prevent that the dynamic way of collaborating ends in chaos and the executing knowledge workers lack systematic support for the tasks (Salter et al. 2014), a specific role model and document templates (artifacts) ensure a flexible but guided and goal-oriented process. These ideas are reflected in the resulting prototype that demonstrates effective solutions to some of the outlined challenges of collaborative OI.

However, especially from the dynamic capabilities point of view limitations regarding the presented approach need to be addressed. It is assumed that chosen innovation ideas and their development lead to market success and thus create new and valuable resources, both in process and product. Consequences that arise with unsuccessful innovation projects or disharmonies between the participating partners are not considered in this paper and necessitate further investigation. Furthermore, as the technical implementation does not encompass all suggestions of the new approach, there is a need for additional research. The most serious limitation is the assumption that as ACM works in the discipline of BPM sharing the same issues with Innovation Management it is also a suitable solution. On this base the requirements of the software tool are derived and implemented. In future, a comparison with the current tool landscape is necessary to answer the question to what extent OI already incorporates solution approaches from ACM. Above all, the contribution shows that a comprehensive portfolio of collaboration features and their interrelations provide a solid base for OI. The concept has been evaluated with experts of the innovation department of a large industrial manufacturer and the results confirm that ACM has proved to be a compelling paradigm to manage the unpredictable nature of innovations.

\section{References}

Beerheide E, Katenkamp O (2011) Wissensarbeit im Innovationsprozess. Innovationsmanagement 2.0. Gabler, Wiesbaden, pp 67-99

Blome C, Schoenherr T, Rexhausen D (2013) Antecedents and enablers of supply chain agility and its effect on performance: a dynamic capabilities perspective. Int J Prod Res 51(4):1295-1318

Burns EV (2011) Case management 101: 10 things you must know about case management. Taming the unpredictable. Future Strategies Inc., Florida, pp 17-26

Camphausen B (2007) Strategisches management: planung, entscheidung, Controlling. Oldenbourg, München

Chakrabarti AK, Hauschildt J (1989) The division of labour in innovation management. R\&D Manag 19(2):161-171

Chesbrough HW (2003) The era of open innovation. MIT Sloan Manag Rev 44(3):35-41

Crawford CM (1994) New products management. The Irwin series in marketing. Irwin, Burr Ridge

Davenport TH (2005) Thinking for a living: how to get better performance and results from knowledge workers. Harvard Business School Press, Boston

Deming WE (1988) Out of the crisis. Massachusetts Institute of Technology, Center for Advanced Engineering Study, Cambridge

Folkerts L, Hauschildt J (2002) Personelle Dynamik in Innovationsprozessen. Die Betr 62(1):7-23

Garriga H, von Krogh G, Spaeth S (2010) How constraints and knowledge impact open innovation. Strateg Manag J 34(9):1134-1144

Gerpott TJ (2005) Strategisches Technologie- und Innovationsmanagement. Schäffer-Poeschel, Stuttgart

Hangos K, Cameron I (2001) Process modelling and model analysis. Academic Press, London

Hauschildt J, Salomo S (2011) Innovationsmanagement. Vahlen, München

Herstatt C (2007) Management der frühen Innovationsphasen: Grundlagen, Methoden, neue Ansätze. Gabler, Wiesbaden

Hevner A, Chatterjee S (2010) Design research in information systems. Integrated series in information systems. Springer, Berlin

Hollingsworth D (2010) Healthcare. Mastering the unpredictable. Meghan-Kiffer, Tampa, pp 163-180 
Howaldt J, Kopp R, Beerheide E (2011) Innovationsmanagement 2.0. Gabler, Wiesbaden

Huber S (2014) Informationsintegration in dynamischen Unternehmensnetzwerken: Architektur. Methode und Anwendung. Springer, Berlin

Huber S, Hauptmann A, Lederer M, Kurz M (2013) Managing complexity in adaptive case management. S-BPM ONE Running Solutions: 5th International Conference S-BPM ONE 2013 Proceedings, pp 209-226

Huber S, Lederer M, Bodendorf F (2014) IT-enabled collaborative case management - principles and tools. In: Proceedings of the 2014 International Conference on Collaboration Technologies and Systems, Minneapolis, IEEE

Huber S, Schott P, Lederer M (2015) IT-enabled adaptive open innovation. In: Proceedings of the 23rd European Conference on Information Systems (ECIS) 2015, Münster

Hughes D, Chafin C (1996) Turning new product development into a continuous learning process. J Prod Innov Manag 13(2):89-104

Khoyi D, Swenson KD (2010) Templates, not programs. Mastering the unpredictable. Meghan-Kiffer, Tampa, pp 145-162

Kline SJ, Rosenberg N (1986) An overview of innovation. The positive sum strategy. National Academy, Washington, pp 275-305

Kolfschoten GL, de Vreede GJ (2009) A design approach for collaboration processes: a multimethod design science study in collaboration engineering. J Manag Inf Syst 26(1):225-256

Kotsemir MN, Meissner D (2013) Conceptualizing the innovation process - trends and outlook. SSRN Electron J. Working Paper WP BRP 10/STI/2013

Kraft FM (2010) Improving knowledge work. Mastering the unpredictable. Meghan-Kiffer, Tampa, pp 181-209

Krzakiewicz K (2013) Dynamic capabilities and knowledge management. Manag 17(2):1-15

Kurz M, Herrmann C (2011) Adaptive case management: Anwendung des BPM 2.0-Konzepts auf wissensintensive schwach strukturierte Geschäftsprozesse. Working Paper

Man HD, Prasad S, van Donge T (2010) Innovation management. Mastering the unpredictable. Meghan-Kiffer, Tampa, pp 211-255

Matthias JT (2010) Technology for case management. Mastering the unpredictable. Meghan-Kiffer, Tampa, pp 63-88

McCauley D (2010) Achieving agility. Mastering the unpredictable. Meghan-Kiffer, Tampa, pp 257-275

Mowery D, Rosenberg N (1979) The influence of market demand upon innovation: a critical review of some recent empirical studies. Res Policy 8(2):102-153

Muscalu E, Stanit A (2013) Knowledge workers - the modern workers prototype in present and future organizations. Ann Univ Oradea Econ Sci Ser 22(2):572-580

Myers S, Marquis DG (1969) Successful industrial innovations: a study of factors underlying innovation in selected firms. Surveys of science resources series 69(17). National Science Foundation, Washington

Pucher MJ (2010) The elements of adaptive case management. Mastering the unpredictable. Meghan-Kiffer, Tampa, pp 89-134

Reichwald R, Piller F (2009) Interaktive Wertschöpfung, Open Innovation, Individualisierung und neue Formen der Arbeitsteilung. GWV Fachverlage, Wiesbaden

Rothwell R (1992) Successful industrial innovation: critical factors for the 1990s. R\&D Manag 22(3):221-240

Rothwell R, Zegveld W (1985) Reindustrialization and technology. Longman, Harlow

Salge TO, Bohné TM, Farchi T, Piening EP (2012) Harnessing the value of open innovation: the moderating role of innovation management. Int J Innov Manag 16(3):1-26

Salter A, Criscuolo P, Ter Wal ALJ (2014) Coping with open innovation: responding to the challenges of external engagement in R\&D. Calif Manag Rev 56(2):77-94

Schwarz S (2014) Service innovation: evaluation of service innovations during exploitation and development. Dr. Kovac, Hamburg

Swenson KD (2010) Mastering the unpredictable - how adaptive case management will revolutionize the way that knowledge workers get things done. Meghan-Kiffer Press, Tempa

Teece DJ (2007) Explicating dynamic capabilities: the nature and microfoundations of (sustainable) enterprise performance. Strateg Manag J 28(13):1319-1350

Teece DJ, Pisano GP, Shuen A (1997) Dynamic capabilities and strategic management. Strateg Manag J 18(7):509-533

Thom N (1992) Innovationsmanagement. Schweizerische Volksbank, Bern

Tidd J (2006) A review of innovation models. Imperial College London, $\mathrm{p} 16$

Usher AP (1954) A history of mechanical inventions. Harvard University Press, Cambridge and Mass

Usher AP (1955) Technical change and capital formation. Capital formation and economic growth. National Bureau of Economic Research, pp 523-550

von Gemünden HG, Walter A (1995) Der Beziehungspromotor: Schlüsselperson für Interorganisationale Innovationsprozesse. J Bus Econ 65:971-986

West J, Bogers M (2014) Leveraging external sources of innovation: a review of research on open innovation. J Prod Innov Manag 31(4):814-831

Witt J (1996) Produktinnovation: Entwicklung und Vermarktung neuer Produkte. Vahlen, München

Witte E (1973) Organisation für Innovationsentscheidungen: Das Promotoren-Modell. Schwartz, Göttingen

Ylimäki J (2014) A dynamic model of supplier-customer product development collaboration strategies. Ind Mark Manag 43(6):996-1004 